\title{
Financial audit of antitachycardia pacing for the control of recurrent supraventricular tachycardia
}

\author{
Michael J Griffith, Rodney S Bexton, Janet M McComb
}

\begin{abstract}
Objective-To assess the financial implications of antitachycardia pacing in patients with frequent supraventricular tachycardia.
\end{abstract}

Patients-Intertach pacemakers were implanted in 25 patients (mean age 47 years, five men): 22 had atrioventricular nodal reentry tachycardia. The patients had failed a mean of 4.9 (range zero to eight) drugs and had been admitted to hospital 3.7 (zero to 31) times over a symptomatic period of 13.9 years (two months to 54 years).

Results-The mean admission time for implantation was $\mathbf{2 \cdot 8}$ (two to seven) days. One patient with Wolff-ParkinsonWhite syndrome subsequently underwent surgery. Infection occurred in two patients, and pain over the pacemaker required its resiting in two. Two patients have had one admission each for tachycardia. Six patients remain on antiarrhythmic drugs. Costs were calculated including value added tax, capital charges, and allocated overheads. The cost a year before pacing was $£ 1174$ including drug costs, clinic visits, and hospital admissions. The mean cost of pacemaker implantation was $€ 3364 \cdot 22$, including the pacemaker and lead, admission and procedure, readmissions and first pacing check. Subsequent annual follow up cost was $£ 73.72$ including annual clinic visits and drug costs. The cost of pacing is $£ 4241$ whereas medical management costs $£ 7044$ assuming pacemaker life of six years: with a 10 year life the cost is $£ 4537$ compared with $£ 11740$ : with a 12 year life the cost is $£ 4685$ compared with $£ 14088$.

Conclusion-The excess cost of implantation of an antitachycardia pacemaker is minimal in patients with frequent supraventricular tachycardia despite drug treatment and is justified by excellent control of symptoms and reduction of drug use and hospital admissions.

(Br Heart f 1993;69:272-275)

Antitachycardia pacing has been established as an effective means of controlling symptoms in patients with recurrent supraventricular tachycardia, especially atrioventricular nodal tachycardia. $^{1-3}$ The cost of this method of treatment has always been assumed to be high due to the cost of the pacemakers used.

The aim of this study was to assess the cost of antitachycardia pacing in relation to hospital admissions, outpatient appointments, and drug use. The effect on demands on the general practitioner service and employment was also sought.

The use of radiofrequency catheter ablation of fast or slow pathways within the atrioventricular node provides an alternative treatment, which may be even more attractive as it can cure the patient. ${ }^{4-8}$ The long-term implications of atrioventricular nodal modification, however, are unknown and fear of late atrioventricular block or ventricular arrhythmias may limit their widespread use until long-term follow up is available.

\section{Patients and methods}

The first 25 consecutive patients who had Intertach pacemakers implanted for the control of recurrent supraventricular tachycardias at this hospital were studied. Their age (mean (range)) was $47(22-72)$ years and 20 were women. The arrhythmia substrate was atrioventricular nodal tachycardia in 22 patients, atrioventricular tachycardia with concealed accessory pathways in two patients, and the Wolff-Parkinson-White syndrome in one patient. The patients had failed a mean 4.9 (range 0 to 8 ) antiarrhythmic drug trials over a mean symptomatic period of 13.9 years (range 2 months -54 years). The patients had had a mean of 3.7 (range 0-31) hospital admissions for tachycardia. Hospital notes were obtained from both Freeman hospital and the referring hospital. The patients were asked to fill in a four page questionnaire, detailing symptoms and hospital admissions, drug treatment, and employment both before and after pacemaker implantation. The general practitioner was also asked to supply details of the number of home visits and surgery consultations, not necessarily related to their tachycardia, in the year before and the year after implantation.

costs

These were calculated at $1990 / 91$ prices (1991/92 prices in parentheses) to include allocated overheads, capital costs at $12 \%$ $(9 \%-12 \%)$, and value added tax at $15 \%$ $(17 \cdot 5 \%)$. Bed days were charged at a standard 
Table 1 Cost of drugs

\begin{tabular}{|c|c|c|}
\hline Drug & $\begin{array}{l}\text { Dose (mg) } \\
\text { (times/day) }\end{array}$ & Cost/yr (Z) \\
\hline $\begin{array}{l}\text { Digoxin } \\
\text { Sotalol } \\
\text { Atenolol } \\
\text { Amiodarone } \\
\text { Quinidine } \\
\text { Verapamil } \\
\text { Diltiazem } \\
\text { Disopyramide } \\
\text { Flecainide } \\
\text { Propafenone }\end{array}$ & $\begin{array}{c}0 \cdot 25(1) \\
80(3) \\
100(1) \\
200(1) \\
300(4) \\
120(3) \\
60(3) \\
150(4) \\
100(2) \\
150(30\end{array}$ & $\begin{array}{r}16 \cdot 28 \\
107 \cdot 55 \\
119 \cdot 14 \\
161 \cdot 48 \\
161 \cdot 74 \\
185 \cdot 17 \\
221 \cdot 01 \\
238 \cdot 65 \\
293 \cdot 16 \\
293 \cdot 16 \\
179 \cdot 90\end{array}$ \\
\hline
\end{tabular}

rate of $£ 153$ ( $£ 202$ ), the average total cost for bed occupancy. Hospital admissions for arrhythmias were assumed to use the equivalent of two bed days. The cost of the pacemaker implantation was calculated on the basis of the actual days in hospital for a pacemaker, the actual implantation, and the cost of admission-procedures, two chest $x$ ray films, two electrocardiograms, a full blood count and electrolytes, and a pacemaker check. The cost of use of a bed was much lower than the average cost quoted above because all expenses incurred by the patient were individually costed. The cost of the pacemaker and lead was that paid to the distributor. Costs for 1991/92 were calculated in a different manner due to a change in accounting practice. Catheter and pacing theatre time was calculated to cost $£ 301$ an hour excluding a major prosthesis such as a pacemaker. Electrophysiology studies were calculated to use $£ 1235$ in prostheses including wastage of electrodes and were calculated for a two hour procedure and a two day admission, a total cost of $£ 2423$.

Outpatient appointments were costed as review appointments at $£ 34 \cdot 72$ (£51). Drug costs were calculated on the basis of monthly prescriptions and a $£ 1 \cdot 20$ prescription charge (the fee for the pharmacist), with the drug costs taken from the British National Formulary, November 1990 (table 1). Drug costs before implantation were calculated in two ways. The mean cost of all drugs used by the patients in the years before implantation was calculated and the cost of the actual drugs used was calculated for the year before implantation. Drug costs after implantation were calculated on the basis of actual drug use. The cost of hospital clinic visits was calculated from the actual events in the year before implantation and was combined with the actual costs. The mean drug costs were combined with assumed hospital costs incurred by four clinic visits and one two day hospital admission. General practitioner costs were not calculated and the effects on employment were also not included in our calculations.

The cost of fast and slow pathway ablation was calculated from the results of Jazayeri and colleagues on the basis of a four (slow pathway) or five (fast pathway) night admission and a procedure time of between 2.5 (slow pathway) and 2.75 (fast pathway) hours. ${ }^{1}$ This procedure included the diagnos- tic study, which we would at present perform as a separate study. The cost was based on Freeman hospital costs and included their reported complications, repeat procedures, and two follow up clinics as well as annual pacemaker checks where appropriate. The ablation catheter (Polaris) costs $£ 595$ and the connector $£ 95$, plus value added tax at $17 \cdot 5 \%$.

\section{PACEMAKER LONGEVITY}

The pacemaker life was calculated with data from the technical manual. The available battery capacity is $1 \cdot 13 \mathrm{Ah}$. Assuming a 500 ohm load, nominal current drain is $11.5(2.0)$ $\mu \mathrm{A}$ in the pacing mode and $8.5(2.5) \mu \mathrm{A}$ in the inhibited mode. Pacemaker longevity was calculated in three ways, all of which assume an output set at $4.0 \mathrm{~V}$ for $0.45 \mathrm{~ms}$, and give the range of possible outcomes (table 2). The mode used at the Freeman when possible is OAO-T, that is, with tachycardia detection and response but no bradycardia support.

\section{Results}

All 25 patients returned their questionnaires and information relating to all admissions was obtained. Over a mean follow up period of 21 (2-42) months, all have had their symptoms well controlled.

\section{PACEMAKER COSTS}

The mean cost of implantation of the pacemakers with a mean inpatient stay of $2 \cdot 8$ (range 2-7) bed days was $£ 490.50$ and the Intertach pacemaker and lead cost $£ 2839.00$. On follow up, 13 of the patients were admitted for a total of 64 days, three for supraventricular tachcardia and 10 for wound related problems. Three patients required repositioning of the pacemaker under general anaesthetic. The patient with Wolff-ParkinsonWhite syndrome underwent surgical ablation of her accessory pathway. The mean cost of the stay in hospital was $£ 398$ for each patient in the total study group. The initial and subsequent hospital admissions were regarded as non-recurring expenses. Six patients remained on antiarrhythmic drugs at a mean cost for the group of $£ 39$ for each patient every year, and an annual outpatient visit was calculated at $£ 34 \cdot 72$ a year, with one extra visit at one month in the first year. The likely life of a pacemaker was calculated by Intermedics to be 12 years.

\section{MEDICAL COSTS}

Table 3 shows the cost for each patient every year before implantation. From the assumed costs the total was $£ 605$ a year and with the actual costs from the year before implantation the total was $£ 1174$.

\section{CATHETER ABLATION COSTS}

These were calculated for the results of Jazayeri and colleagues in 49 patients and included costs for second attempts, failure, and permanent pacing. ${ }^{7}$ They were successful with fast pathway ablation in 15 of 19 
Table 3 Medical treatment (annual cost $(£)$ calculated in two ways)

\begin{tabular}{lcc}
\hline \multicolumn{1}{c}{$1990 / 91$} & $1991 / 92$ \\
\hline \multicolumn{3}{c}{ Based on assumption of one drug being used, four clinic visits, and } \\
one hospital admission \\
Drug costs & 163 & 167 \\
OPD costs 4 & 139 & 204 \\
Admissions 1 & 303 & 404 \\
Cost/yr & 605 & 775
\end{tabular}

Based on the actual cost of the year before pacemaker implantation Drug costs

Admissions 2.6 (0-16) $775(0-4848)$

Cost/yr

1174

277
189

105

1051
1516

OPD, out patient department

patients (three after failed slow pathway ablation in the same procedure) with a mean time of operation of 165 minutes. A permanent pacemaker was implanted in three patients for complete heart block (average unit cost of DDD pacemaker at Freeman Hospital was f1811). One patient with complete heart block already had a pacemaker for sick sinus syndrome. They were successful with slow pathway ablation in 32 of 35 patients, two (one at a separate procedure) of whom had successful fast pathway ablation, but a slow tachycardia remained. Mean time of operation was 151 minutes. We assumed five bed nights for the fast pathway ablation (longer because of the risk of late complete heart block) and four bed nights for slow pathway ablation, a total of two follow up clinics and annual pacemaker checks for four patients. Table 4 shows costs.

\section{COMPARATIVE COSTS}

Tables 4 and 5 show the cumulative cost of continued drug treatment compared with pacemaker implantation and subsequent follow up. The assumed medical costs are almost equal to the pacemaker costs at six years but are much more at 10 and 12 years. Longevity of a pacemaker with OAOT mode ranges from 12.2 to $19 \cdot 8$ years (table 1 ). The actual medical costs are nearly double the pacemaker costs at six years and some three times the costs at 12 years.

Table 4 shows the comparison of antitachycardia pacing with medical treatment and catheter ablation. Selective atrioventricular nodal pathway ablation was the cheapest method and was even cheaper if costs of a diagnostic electrophysiological study was added to the cost of a pacemaker (as was done at the time of ablation by Jazayeri and colleagues).

Table 4 Comparisons of costs at 1991/92 prices $(£)$

\begin{tabular}{llrr}
\hline \multicolumn{3}{l}{ Pacemaker life } \\
\cline { 2 - 4 } & $6 y r$ & $10 y r$ & $12 y r$ \\
\hline Pacemaker & 5,009 & 5,373 & 5,556 \\
Pacemaker + EP & 7,432 & 7,792 & 7,979 \\
Medical assumed & 4,620 & 7,750 & 9,300 \\
Medical real & 9,098 & 15,164 & 18,968 \\
Ablation & 4,552 & 4,569 & 4,577 \\
\hline \multicolumn{4}{l}{ EP, cost of two day admission and electrophysiology study. }
\end{tabular}

Table 5 Comparisons of costs at $1990 / 91$ prices $(£)$

\begin{tabular}{llrr}
\hline & \multicolumn{3}{l}{ Pacemaker life } \\
\cline { 2 - 4 } & $6 y r$ & $10 y r$ & $12 y r$ \\
\hline Pacemaker & 4,241 & 4,537 & 4,685 \\
Medical assumed & 3,630 & 6,050 & 7,260 \\
Medical real & 7,044 & 11,740 & 14,088 \\
\hline
\end{tabular}

\section{EMPLOYMENT}

Before implantation nine patients were in full time work, one was in part time work, two were retired, three were not in work and 10 were housewives. After implantation the only changes were the part time worker and one of those not in work who became full time workers.

\section{GENERAL PRACTITIONERS}

Information on the number of consultations for any reason was received from 14 general practitioners. In nine the number of consultations had fallen, in one it had stayed the same and in four there had been an increase in consultations. The mean (SD) number of consultations in the year before implantation was $10.7(7 \cdot 2)$ and $8.0(6.5)$ in the year after implantation ( $\mathrm{p}=0.045$, two tailed $t$ test).

\section{Discussion}

The major difficulty in justifying high technology medicine is that the marginal costs seem much greater than those of conservative treatment. This is because it is easier to calculate the cost of a single procedure, with an expensive piece of equipment, than it is to calculate the continuing costs of conservative, usually drug based, treatment.

These data show that implantation of an expensive antitachycardia pacemaker may actually save money after six years and these can be appreciable at the pacemaker's expected life of 12 years. This saving is purely in terms of hospital costs and ignores the benefits in quality of life and employment, or the effect of demands on the family doctor, although all of these seem to be improved after implantation.

In making these calculations it has been necessary to make assumptions. In a "free at the point of use" service all hospital costs have to be estimated, although this is aided by our being a Trust. The drug and equipment costs are accurate, but the use of medical resources during conservative treatment are necessarily an estimate. The real figure may be between our two estimates, as patients with recurrent tachycardias despite multiple drug treatment are likely to be treated with new drugs as they are available, and these are usually the most expensive. Prolonged episodes requiring admission and frequent clinic appointments are also likely to remain necessary as long as the arrhythmia is poorly controlled. The need for only one annual clinic appointment (after the first year) after pacemaker implantation may seem low, but this is our actual practice. Even if there were two clinic visits a year this would only increase the total cost over six years by 
$£ 208 \cdot 32$, or $£ 416 \cdot 64$ over 12 years. We have included the costs of invasive electrophysiological investigation seperately in the cost of antitachycardia pacing. This is part of the routine investigation of patients with paroxysmal tachycardia referred to a tertiary referral centre for investigation, and will be performed even in patients who then continue to be managed with antiarrhythmic drugs. This paper gives the financial implications of the choice of treatment after the electrophysiological diagnosis has been established.

The recent development of surgical or catheter ablation techniques may present even more attractive financial benefits over conservative drug treatment. This is probably already true of patients with an accessory pathway distant from the AV node, ${ }^{45}$ but it is the patients with atrioventricular nodal reentry tachycardia who are most suitable for antitachycardia pacing. Whereas these patients may be cured of their tachycardia by ablation of slow or fast pathways, the longterm effect of such treatment needs further study. ${ }^{5-9}$ Acute or chronic complete or partial atrioventricular block may result in an unknown proportion of these patients who then require dual chamber pacing. ${ }^{6} 7$ The advantage of antitachycardia pacing is that it is easily reversed, and a second treatment such as catheter ablation may be used if it is unsuccessful or when the long-term implications of ablation are clearer. We have calculated the costs of pathway ablation from the figures of Jazayeri and colleagues ${ }^{7}$ because our experience is as yet too small. This is dramatically cheaper than medical treatment, especially after 10 years but is only marginally cheaper than antitachycardia pacing. They included the diagnostic electrophysiological study in their ablation procedure, but this is unlikely to have taken much more time than a straight ablation where the same catheters would be introduced and antegrade and retrograde curves repeated before ablation. We at present perform a separate diagnostic electrophysiological study in all patients, but if this were combined in the ablation procedure then its cost advantage is further increased. Also the cost of ablation may be reduced if the duration of time in hospital for ablation in the United Kingdom is shorter than the four to five days these authors quoted. If the follow up of patients who have undergone catheter ablation of atrioventricular slow or fast pathways shows that it is safe and effective in the long-term, it is likely to replace antitachycardia pacing as the nonpharmacological treatment of choice on clinical and financial grounds.

To conclude, the excess cost of implantation of an antitachycardia pacemaker is minimal in patients with frequent supraventricular tachycardia despite drug treatment and is justified by excellent control of symptoms and reduction of drug use and hospital admissions.

1 Fisher JD, Kim SG, Mercando AD. Electrical devices for treatment of arrhythmias. Am $\mathcal{F}$ Cardiol 1988;61:45-57.

2 Jung W, Mletzko R, Manz M, Luderitz B. Comparison of two anti-tachycardia pacing mode in supraventricular tachycardia. PACE 1991;14:1762-6.

3 McComb JM, Jameson S, Bexton BS. Antitachycardia pacing in patients with supraventricular tahycardias: experience with the Intertach pacemaker. $P A C E$ experience with

4 Jackman WM, Wang $\mathrm{X}$, Friday $\mathrm{KJ}$, et al. Catheter ablation of accessory atrioventricular pathways (WolffParkinson-White Syndrome) by radiofrequency ablation. New Engl f Med 1991;324:1605-11.

5 Calkins H, Souza J, El-Atassi R, Rosenheck S, De Buitlei $M$, Kou WH, et al. Diagnosis and cure of the WolffParkinson-White syndrome or paroxysmal supraventricular tachycardias during a single electrophysiologic test New Engl ₹ Med 1991;324:1612-8.

6 Goy J, Fromer M, Schlaeper J, Kappenberger L. Clinica efficacy of radiofrequency current in the treatment of patients with atrioventricular node reentrant tachycardia. ₹ Am Coll Cardiol 1991;16:418-23.

7 Jazayeri MR, Hempe SL, Jasbir SS, Dhala AA, Blanck Z, Deshpande SS, et al. Selective transcatheter ablation of fast and slow pathways using radiofrequency energy in fast and slow pathways using radiofrequency energy in patients with atrioventricular nodal
dia. Circulation 1992;85:1318-28.

dia. Circulation 1992;85:1318-28.
8 Wang X, McClelland JH, Beckman KJ, Hazlitt HA, Prior $\mathrm{MI}$, et al. Accelerated junctional rhythm during slow pathway ablation. Circulation 1991;84:II-582.

9 Cox JL, Ferguson TB, Lindsay BD, Cain ME. Perinodal cryosurgery for atrioventricular node reentry tachycardia in 23 patients. $\mathcal{F}$ Thorac Cardiovasc Surg 1990;99:440-9. 